\title{
Effect of Curcumin in Diabetes mice Induced by Streptozotocin
}

\author{
M.S. MIAO, T. WANG, Y.Li, Y.Y. MIAO, M. BAI \& W.Y.Xin \\ Henan university of traditional Chinese medicine, zhengzhou, henan 45000, China
}

ABSTRACT: Object To investigate the effect and mechanism of curcumin in diabetes mellitus mice. Methods Diabetic models were induced by a single vena caudalis injection of streptozotocin(STZ)into mice at a dose of $50 \mathrm{mg} \cdot \mathrm{kg}-1$ body weight and was randomly divided into five groups:untreated diabetes group,diabetes group treated with large, middle, small dose of curcumin and diabetes group treated with Diamicron.And another was a normal control group.the group of curcumin treated with large, middle, small dose of curcumi for 30 days. When the tenth, twentieth,detect the blood glucose of mice. When the thirtieth day detect the blood glucose (BG), insulin, Glycated serum protein(GSP) in blood serum, hepatic glycogen in liver homogenate and observe the pathological change of pancreas. Results Diabetes group treated with large, middle, small dose of curcumin had significant statistical significance. And the curcumin had a significant effect in the treatment of diabetes mice induced by streptozotocin.Compared with the model group,the group of curcumin could obviously degrade the level of $\mathrm{BG}$ and $\mathrm{GSP}(\mathrm{P}<0.05)$; and could markedly ameliorated the lesions of pancreas $(\mathrm{P}<0.01)$. The large dose of curcumin could remarkably elevate the level of hepatic glycogen and the insulin in blood serum $(\mathrm{P}<0.01)$.the middle dose of curcumin could obviously elevate the level of hepatic glycogen and the insulin in blood serum $(\mathrm{P}<0.05)$. The small dose of curcumin could obviously elevate the level of insulin in blood serum $(\mathrm{P}<0.05)$. Conclusion:Curcumin may decrease the level of BG and GSP in blood serum of diabetic mice at early stage, elevate the level of insulin and hepatic glycogen, and alleviate pancreas affection caused by diabetes.

KEYWORD: Curcumin; Diabetic mellitus; blood glucose; Streptozotocin

\section{INTRODUCTION}

Diabetes mellitus (DM), which is a comprehensive and progressive disease caused by high concentration of blood sugar, has much complication which were serious[1]. Its morbidity is gradually raising, along with productive forces development, living standard enhances and duration of life extension, diabetes mellitus morbidity grows rapidly. According to 2013 data, diabetes patients has reached more than 4000 million[2]. Nowadays it has become one of the more and more general public health problems all over the world. To study and research a drug to treat DM has became a imperative problem.

Curcumin is a alcohol phenyl colorant extract from Rhizoma Curcumae Longae, Radix Curcumae and Rhizoma Curcumae, which possess the pharmacologic action of antioxidative, cleaning free radical and so on,but concerning the effect of degrading the $\mathrm{BG}$ and its mechanism reported less in and abroad country[3]. This article aims to investigate the effect and mechanism of curcumin in hyperglycemic mice. Methods.

\section{MATERIAL}

\subsection{Animal}

Mouse: Kunming strain, maleness, body mass (BM)18 22g, provided by Laboratory Animal Facility in Henan Province, NO.410115(mouse).

\subsection{Drug and reagent}

Curcumin, provided by Henan Gangye Pigment Co., Ltd, content greater than 90\%; Diamicron(Gliclazide Tablets),provided by France Servier pharmaceutical factory/Tianjin Huajin pharmaceutical factory, Batch No.:011129, etalon:80mg/tablet,60tablets/caddy;Stre ptozotocin(STZ): provided by Sigma company; Blood glucose reagent case: provided by Baoding Great Wall Clinical reagents Co.Ltd., Batch No.:030321; Physiological saline, produced by 
Zhengzhou Chemical and Medico-Industry Limited Company, Batch No.:030409, Ord: 500ml/bottle; Formaldehyde: produced by YanTai Shuangshaung Chemical industry Ltd,Batch No.:030122, Ord:500ml/bottle; CMC-Na: produced by Shanghai Chemical Reagent Company packaging plant,Batch No.:030526.

\subsection{Instrument}

752-spectro photometer: produced by Shanghai Third Analytical Instrument Factory

Homeothermia thermostat-controlled. 8002 waterbath: produced by Beijing Guangming medical treatment Instrument Factory. Mechanical transferettor: produced by Thermo Labsystems (Shanghai) Co.Ltd.

\section{METHOD}

\subsection{DM mice model induced by STZ}

Absolute diet for 12 hours, single vena caudalis injection of streptozotocin (STZ)into mice at a dose of $50 \mathrm{mg} \cdot \mathrm{kg}-1$ body weight to pose a DM mice model[4].

\subsection{The influence of curcumin in DM mice model}

After vena caudalis injection of streptozoticin(STZ) for 72 hours, gain the blood by snipping tail to determine the $\mathrm{BG}$, select the mice which BG $>11.1 \mathrm{mmol} / \mathrm{L}$, and obviously drinking, eating, urining, then divide them into five groups: untreated diabetes group treated with $0.5 \% \mathrm{CMC}$, diabetes group treated with large, middle, small dose of curcumin $\left(400 \mathrm{mg} \cdot \mathrm{kg}^{-1}, 200 \mathrm{mg} \cdot \mathrm{kg}^{-1}, 100 \mathrm{mg} \cdot \mathrm{kg}^{-1}\right.$, prepare the concentration of $20 \mathrm{mg} \cdot \mathrm{ml}^{-1}, 10 \mathrm{mg} \cdot \mathrm{ml}^{-1}$, $5 \mathrm{mg} \cdot \mathrm{ml}^{-1}$ by $0.5 \% \mathrm{CMC}$, intragastric administration volume is $0.02 \mathrm{ml} \cdot \mathrm{g}^{-1}$ ) and diabetes group treated with Diamicron $\left(0.5 \% \mathrm{CMC}, 80 \mathrm{mg} \cdot \mathrm{kg}^{-1}, \quad 4 \mathrm{mg} \cdot \mathrm{ml}^{-}\right.$ $\left.{ }^{1}, 0.02 \mathrm{ml} \cdot \mathrm{g}^{-1}\right)$ A normal control group was also designed treated with $0.5 \% \mathrm{CMC}$,once a day, treated for 30 days. when the tenth, twentieth, thirtieth day, determine the blood glucose of mice respectively.
After the last administration, determine the blood glucose (BG), insulin, Glycated serum protein (GSP) in blood serum, hepatic glycogen in liver homogenate and observe the pathological change of pancreas.

\subsection{Observation index and method}

BG:on the tenth, twentieth, thirtieth day, absolute diet for 12 hours, then get the blood, determine the blood glucose according to the reagent case. Insulin, GSP: segregate the blood serum, determine them by spectro photometer according to the reagent case. hepatic glycogen: separate liver and make the liver homogenate, marching it according to the reagent case. pathological change of pancreas: fixed pancreas by $10 \%$ Formaldehyde, anhydration, soak cera, embed, blade, HE dyeing, observe the pathological change of pancreas by light microscope.

\subsection{Statistical treatment}

Data analysis used SPSS 13.0 for statistical treatment[5]. measurement data represented by mean \pm variance $(x \pm \mathrm{s})$, group comparison used analysis of variance; ranked data used Ridit test.

\section{RESULT}

\subsection{The effect of Curcumin on the BG of DM mice model induced by $S T Z$}

Discern from table 1, except blank control group, the BG of other groups don't have marked disparity, which demonstrate that the grouping is adqulis. comparing with normal control group, the level of BG in tenth, twentieth, thirtieth day was significantly increased, which demonstrated the DM model was doing well. Comparing with untreated diabetes group, in tenth day, the large, middle dose of curcumin and Diamicron could obviously degrade the level of BG $(P<0.05)$; in twentieth day, the large, middle and small dose of curcumin could obviously degrade the level of BG $(\mathrm{P}<0.05)$, Diamicron could

Table 1. the effect of Curcumin on the BG of DM mice model induced by STZ $(\bar{x} \pm \mathrm{s}, \mathrm{mmol} \cdot \mathrm{L}-1)$

\begin{tabular}{|l|c|c|c|c|c|c|}
\hline groups & $\begin{array}{c}\text { animal } \\
\text { quantity }\end{array}$ & $\begin{array}{c}\text { dosage } \\
(\mathrm{mg} \cdot \mathrm{kg}-1)\end{array}$ & Incipient BG & Tenth day & twentieth day & thirtieth day \\
\hline normal control group & 10 & - & $5.47 \pm 0.95$ & $5.58 \pm 0.85^{* *}$ & $5.65 \pm 0.70^{* *}$ & $5.21 \pm 0.54 * *$ \\
\hline untreated diabetes group & 10 & - & $16.66 \pm 4.97$ & $19.71 \pm 0.06$ & $24.36 \pm 7.56$ & $20.60 \pm 6.07$ \\
\hline Diamicron group & 10 & 80 & $16.12 \pm 5.41$ & $13.34 \pm 6.98 *$ & $14.38 \pm 7.27 * *$ & $11.84 \pm 6.08 * *$ \\
\hline Large dose of curcumin group & 10 & 400 & $16.47 \pm 4.23$ & $12.85 \pm 7.11 *$ & $15.27 \pm 7.48^{*}$ & $11.10 \pm 6.62 * *$ \\
\hline middle dose of curcumin group & 10 & 200 & $16.61 \pm 4.69$ & $13.53 \pm 6.76^{*}$ & $16.13 \pm 7.63^{*}$ & $13.76 \pm 3.45^{* *}$ \\
\hline Small dose of curcumin group & 10 & 100 & $16.50 \pm 5.26$ & $16.16 \pm 6.34$ & $16.44 \pm 7.09^{*}$ & $14.03 \pm 5.36^{*}$ \\
\hline
\end{tabular}


remarkably degrade the level of $\mathrm{BG}(\mathrm{P}<0.01)$; in thirtieth day, the large, middle dose of curcumin and Diamicron could remarkably degrade the level of $\mathrm{BG}(\mathrm{P}<0.05)$, the small dose of curcumin could obviously degrade the level of $\mathrm{BG}(\mathrm{P}<0.05)$.

\subsection{The effects of Curcumin on the hepatic glycogen, insulin and GSP of DM mice model induced by STZ}

Discern from table 2, comparing with normal control group, the level of hepatic glycogen, insulin in untreated diabetes group was remarkably degraded
$(\mathrm{P}<0.01)$, the level of GSP was remarkably increased $(\mathrm{P}<0.01)$, which demonstrated the DM model was doing well. Comparing with untreated diabetes group, the large dose of curcumin could remarkably elevate the level of hepatic glycogen $(P<0.01)$, the middle dose of curcumin could obviously degrade the level of hepatic glycogen $(P<0.05)$; the large dose of curcumin and Diamicron could remarkably elevate the level of insulin $(P<0.01)$; the large, middle dose of curcumin could obviously degrade the level of GSP $(P<0.05)$, the small dose of curcumin could obviously degrade the level of BG $(P<0.05)$.

Table 2 the effects of Curcumin on the hepatic glycogen, insulin and GSP of DM mice model induced by STZ ( $\left.\bar{x}_{ \pm \mathrm{s}}\right)$

\begin{tabular}{|l|c|c|c|c|c|}
\hline groups & $\begin{array}{l}\text { animal } \\
\text { quantity }\end{array}$ & $\begin{array}{l}\text { dosage } \\
(\mathrm{mg} \cdot \mathrm{kg}-1)\end{array}$ & $\begin{array}{l}\text { hepatic glycogen }(\mathrm{mg} \cdot \mathrm{g}-1 \\
\text { humid weight of liver })\end{array}$ & Insulin $(\mathrm{u} \cdot \mathrm{ml}-1)$ & $\mathrm{GSP}(\mathrm{mmol} \cdot \mathrm{L}-1)$ \\
\hline normal control group & 10 & - & $7.66 \pm 1.46^{* *}$ & $14.91 \pm 7.05^{* *}$ & $2.03 \pm 0.25^{* *}$ \\
\hline untreated diabetes group & 10 & - & $3.17 \pm 1.44$ & $3.92 \pm 2.68$ & $2.70 \pm 0.39$ \\
\hline Diamicron group & 10 & 80 & $3.54 \pm 1.88$ & $9.56 \pm 4.45 * *$ & $2.39 \pm 0.37$ \\
\hline Large dose of curcumin group & 10 & 400 & $6.16 \pm 1.18^{* *}$ & $9.74 \pm 3.88^{* *}$ & $2.31 \pm 0.34 *$ \\
\hline middle dose of curcumin group & 10 & 200 & $5.13 \pm 1.80 *$ & $7.43 \pm 3.02 *$ & $2.32 \pm 0.38^{*}$ \\
\hline Small dose of curcumin group & 10 & 100 & $4.01 \pm 1.87$ & $6.99 \pm 2.50^{*}$ & $2.44 \pm 0.35$ \\
\hline
\end{tabular}

*:comparing with untreated diabetes group $\mathrm{P}<0.05$.

**: comparing with untreated diabetes group $\mathrm{P}<0.01$.

\subsection{The effect of Curcumin on the pancreas of DM mice model induced by STZ}

The results of pathological change of pancreas: the normal control group have more bigger islet of Langerhans, affluent cytolymph, fluffy cell nucleus; the untreated diabetes group have conspicuously decreased islet of Langerhans, obviously decreased cytolymph, more conferted cell nucleus; the Diamicron group have decreased cytolymph of partly cells, little fluffy cell nucleus; the volume of islet of Langerhans augment in the large dose of curcumin group, also the cytolymph increased and a part of cell nucleus relatively concentrate; the volume of islet of Langerhans augment a little in the middle dose of curcumin group, also the cytolymph increased and a part of cell nucleus relatively concentrate; the volume of islet of obviously deflate in the small dose of curcumin group, also most cytolymph decreased and cell nucleus concentrated.

Table 3 the effect of Curcumin on the pancreas of DM mice model induced by STZ

\begin{tabular}{|c|c|c|c|c|c|c|}
\hline groups & animal quantity & Dasage $\left(\mathrm{mg} \cdot \mathrm{kg}^{-1}\right)$ & - & + & ++ & +++ \\
\hline normal control group & 10 & - & 10 & 0 & 0 & 0 \\
\hline untreated diabetes group & 10 & - & 0 & 1 & 2 & 7 \\
\hline Diamicron group & 10 & 80 & 0 & 6 & 4 & 0 \\
\hline Large dose of curcumin group & 10 & 400 & 2 & 6 & 2 & 0 \\
\hline middle dose of curcumin group & 10 & 200 & 1 & 5 & 4 & 0 \\
\hline Small dose of curcumin group & 10 & 100 & 0 & 3 & 7 & 0 \\
\hline
\end{tabular}

“-" singulorum category cells of the islet of Langerhans have affluent cytolymph,the volume augmented, the volume of islet of Langerhans augmented; "+"a little part of islet cell emerge that the cell analosis, cytolymph obviously decrease,volume deflate; “++" islet cell partly analosis, cytolymph obviously decrease, caryon concentrated;partly have affluent cytolymph, volume augmente; "+++" islet cell emerged subtotal analosis, cytolymph obviously decrease in most cells, caryon concentrated in large-area, the volume of the islet of Langerhans obviously deflate.

Discern from table 3, except blank control group, some damage in different degree all emerged in other groups, especially the untreated diabetes group, through the Ridit test, comparing with normal 
control group, the pathological change of pancreas in untreated diabetes group is most remarkablethe $(P<0.01)$, which demonstrated the DM model was doing well. Comparing with untreated diabetes group, the large, middle, small dose of curcumin and Diamicron could remarkably abate the pathological change of pancreas $(P<0.01)$, especially the the large dose of curcumin.

\section{CONCLUSIONS}

Hypoglycemic activity the DM model induced by streptozotocin (STZ) frequently used as bolting the hypoglycemic drug. Accordingly [6]. This experiment select a commonly used STZ mice model, investigate the dynamic state course of BG.

As a monitoring index for therapeutic effect evaluation of diabetes mellitus and the one of a dangerous factor of DM vasculopathy [7], Glycosy lated Serum Protein (GSP) is reconstructing on clinic [8]. As one of the storage form of carbohydrates, glycogen participates in the regulation of the body's blood glucose level. And its synthesis and degradation controlled by insulin. there would be Resulting in an increase in glycogen breakdown when the regulation system disorders[9]. It will also lead to disorders of glucose metabolism when lacking of insulin secretion[10-11]. Thereby The body's blood sugar rises and urine appears. So glycogen and glycosy lated Serum insulin is a facility index for observation in DM.

This investigation discovered that comparing with curcumin group, the group of curcumin could obviously degrade the level of BG and GAP; and could markedly ameliorated the lesions of pancreas. The large dose of curcumin could remarkably elevate the level of hepatic glycogen and the insulin in blood serum. the middle dose of curcumin could obviously elevate the level of hepatic glycogen and the insulin in blood serum. The small dose of curcumin could obviously elevate the level of insulin in blood serum.

The study found that the group of curcumin could obviously degrade the level of BG, GSP, insulin in the blood serum, and the glycogen. It could also protect the pancreas. And the curcumin had a significant effect in the treatment of diabetes mice induced by streptozotocin. This is not only providing experimental support but providing new ideas and methods for the clinical treatment of curcumin in streptozotocin -induced diabetic.

\section{REFERENCES}

[1] Wei Li-xin, Xu Zhong-xin, Tian he lin. Evaluation and establishment of Streptozotocin-induceddiabetic model in mouse Chin J Lab Diagn, 2013, 17(5):806-808.

[2] SU Jin. Clinical characteristics and therapeutic efficacy analysis of Diabetes complicated by ischemic encephalopathy Jilin Medical, 2013, 34(16).

[3] Luo Yan-shun, Li Hong-wen, Liu Zheng-wen. Advances in studies on extraction, separation, and pharmacological action of curcumin. Drugs \& Clinic, 2011, 26(2):102-107.

[4] Sun Wei, Gao Xin, Liu Zhi-hui. Intervention of C-peptide on diabetic nephropathy in streptozotocin induced diabetic rats. Chin J Endocrinol Metab, 2003, 19(2):143144.

[5] HUANG Bo, LIU Xue-zheng, PANG Dong-bo.Study on Diabetic Model in Rats Induced by Streotozotocin in Different Ways. J Jinzhou Med College, 2003, 24(1): 1921.

[6] GUO Yan-min. Studies on the Weight and Dose Affecting the Mice Diabetic Model Induced by Streptozocin. Animal Husbandry and Feed Science, 2011, 32(12):17-18.

[7] Zhong Yan-fa. Combined detection of glucose, glycated serum protein, D-3 hydroxybutyrate application in diabetic. Chinese Journal of Medicinal Guide, 2013, 15(S):191-192.

[8] Liu Zhi-jun, Tan Dong yun, Rao Rong. Glycated hemoglobin, glycated serum protein detection applications combined in identifying the nature of hyperglycemia. Journal of Chinese Practical Diagnosis and Therapy, 2011, 25(1):67-68.

[9] SONG Baihui, CHENG Yunlong, XIN Xirui. Effects of Ehanol Extract of Rhizoma Phragmitis on Liver Glycogen Content and Glycogen Synthetase in Diabetic Mice Tianjin Med J, 2014, 42(1):65-67.

[10] ZHANG Pu, LI Rongrong, LI Yixin. Establishment of Type 1 Diabetic Mouse Models and Study on the Expression Changes of Insulin in Islet B Cells. JOURNAL OF GUIYANG MEDICAL COLLEGE, 2014, 39(2):171-175.

[11] Guo Xue-ying, Wang Wei-ming. Diabetes and its pathogenesis. Technology rich wizard, 2012, 9:194. 